\title{
CHALLENGES OF POSITIVE PARENTING FOR ESPECIALLY ABLED CHILDREN: MANAGEMENT AND COPING
}

\author{
Nazir Ahmad Kotey ${ }^{1}$ and Fayaz Ahmad Kotay ${ }^{2}$ \\ ${ }^{1}$ Head, Department of Sociology, Govt. Degree College for Women, \\ Anantnag, Jammu and Kashmir \\ ${ }^{2}$ Lecturer, School Education, Jammu and Kashmir \\ Email: drjanmohammad037@gmail.com
}

How to cite this paper:

Kotey, Nazir Ahmad and

Kotay, Fayaz Ahmad (2021)

Challenges of Positive

Parenting for Especially

Abled Children:

Management and Coping, Journal of Global Resources, Vol. 07 (02)

DOI:

10.46587/JGR.2021.v07i02.010

Received: 21 March 2021

Reviewed: 10 April 2021

Revised: 11 May 2021

Final Accepted: 18 May 2021

\begin{abstract}
Contrastingly abled youngsters' methods a kid" with mental impediment, hearing weaknesses (including deafness) discourse or language hindrance, visual debilitation( including visual deficiency) genuine enthusiastic aggravation, muscular hindrance, chemical imbalance, horrendous cerebrum injury, other wellbeing impedances or explicit learning handicaps and who by reason thereof, need specialized curriculum and related administrations" Family is the essential unit of government managed retirement for each person, old or youthful, male or female ,sound or wiped out, capable bodies or incapacitate. In families having people with an inability (physical or mental), the requirements and duties of the family unquestionably expands complex. Before, guardians were typically encouraged to institutionalize their intellectually hindered youngster yet it's anything but a patricide any longer.
\end{abstract}

Keywords: Children, Retardation, Disabled, Social, Family, Security 


\section{Introduction}

The term inability is for the most part used to allude a condition, which is coming about because of disfunction in singular bodies, and psyche subsequently influences one's typical life exercises. Handicap is a socially, socially and hypothetically complex subject. As per the Persons with Disabilities (Equal Opportunities, Protection of Rights and Full Participation) (PWD) Act, 1995, seven classes of handicaps have been characterized.

(a) "Visual deficiency" alludes to a condition where an individual experiences any of the accompanying conditions, in particular: (i) Total shortfall of sight; or (ii) Visual keenness not surpassing $6 / 60$ or $20 / 200$ (snellen) in the better eye with adjusting focal points; or (iii) Limitation of the field of vision subtending a point of 20 degrees or more regrettable

(b) "Individual with Low Vision" signifies an individual with hindrance of visual working even after treatment or standard refractive revision yet who utilizes or is possibly equipped for utilizing vision for the arranging or execution of an undertaking with fitting assistive gadgets.

According to WHO inability is an umbrella term, covering weaknesses, action impediments and support limitations. An impedance is an issue in body capacity or design; an action constraint is a trouble experienced by a person in executing an errand or activity; while an investment limitation is an issue experienced by a person in contributions in life circumstances subsequently, incapacity isn't just an issue of medical issue. It is an unpredictable wonder, mirroring the connection between highlights of an individual's body and highlights of the general public wherein the person lives. Joined Nations Convention on the Rights of Persons with Disabilities (UNCRPD) says, people with inabilities incorporate the individuals who have long haul physical, mental, scholarly or tactile hindrances, which in communication with different obstructions may block their full and compelling support in the public arena on an equivalent premise with others [1-3]. In succeeding conversation, the creator has attempted to zero in on the calculated model of handicap that will help in more profound comprehension about inability from different measurements. The short sketch of different models is:

\section{Medical Model}

The medical model interprets the disability as a bodily impairment which is dealt by the medical professionals. This disability is considering as a fixed, permanent, or static one. The medical model of disability only focuses the individual's limitations.

\section{Social Model}

The social model of disability says that disability is caused by the way society is organizing, rather than by a person's impairment or difference. Social model refers the disability as a disabling social, environmental and attitudinal barrier rather than lack of ability of the body. Disability is not an attribute of an individual, but rather a complex collection of conditions which may create by the social environment.

\section{Minority Model}

A major chunk of the population in our society suffers this problem which create a group known as minority group. The minority model, in which disability is theorized partly as a form of cultural otherness, probably fits the case of deaf people best. The capital is intended to mark deafness as a cultural and linguistic identity. In past era, a distinct class of the population has been referred as a disability population. This class of the population had less power and subject to stigmatize and exclusion.

\section{Gap Model}

The dominant paradigm, the relational or gap model in which disability is theorizing as a difference between the capabilities of the individual and the demands of society, is fit for certain 
purposes, the most important of which is to identify areas of adaptive improvement. The gap model's notion that "disablement" can actually be eliminated through the simultaneous adjustment of individual capacities and social demands is an ideological position that requires a significant degree of mutual interest between individual and state. Disability is explained as the gap between those capabilities and the opportunities offered by society and its institutions; disability is therefore something that can and should be addressed by the full spectrum of policy tools, ranging from medical intervention, when appropriate, to anti-discrimination measures directed at employers, academic institutions, commercial entities, etc. The gap model does not take a position on this issue, but merely acknowledges that a proportion of the population will at any given time have either impairments or illness that place certain restraints on their functional capacities [4].

\section{Ecological Model}

It focuses the disability is a result of interaction of impairment, activity limitations and participation restriction in a particular social or any physical environment like place of work, home, school, or any public places etc.

\section{Magnitude of disability in India}

India is the largest democracy with an estimated population of $121,08,54,977$ as per census of India, 2011. It has one of the highest densities of population in different religion, culture, ethnicity and belief. The geographical and culturally heterogeneous country India can be also characterized due to feature of disability as largest minority group. In India, two officially departments collect disability statistics i.e., NSSO (National Sample Survey Organization) and census of India. After independence India census 1981 has started to collect the data on disability which comprise 0.2 percent of total population. No data was collected in the 1991 census. The year 1991 which indicates that about 1.9 percent of the total population (16.15 million population) of the country have disabilities. According to the census 2001 there were 21.9 million persons with disabilities compared with 18.5 million (1.8 million of the total population). Census 2011 shows that 2.21 percent of the total population have disabilities. Table-1 explains the percentage of different types of disabilities as a whole with the rural and urban settings also. Census 2011 shows that the prevalence of disability is higher in rural areas in comparison to urban areas [5][6]. All types of disabilities and their percentages is mentioned in table-1\& 2.

\section{Parental Acceptance, Management and Coping}

Exploration demonstrates that family response to the introduction of an incapacitated youngster changes as indicated by the kind of handicap and the kid's analytic class. The distinctions are most likely an aberrant result of expected or genuine responses by those encompassing the handicapped kid and the family, notwithstanding parental responses. Numerous scientists have as of late referenced the positive adapting and working of numerous families with formatively crippled kids. In the past there was an inclination to stress issues of sickness and pressing factors, spousal strain and maladjustment inside the family, while as of now they are supplanted with questions concerning positive change, fulfilment, acknowledgment, and spousal congruity. Instead of seeing the family as a powerless casualty, it is seen as a unit that adjusts by an interaction of organizing. Experts should recognize the significance of the family, this change towards an uplifting mentality towards incapacity and that the controls choices concerning the incapacitated youngster and the family. Guardians are the focal and most significant connection in the consideration, training, and management of people with handicap. 
Table 01: Percentage of disabled persons by types of disability in rural and urban India

\begin{tabular}{|c|c|c|c|c|c|c|c|c|c|}
\hline Population & \multicolumn{3}{|c|}{ Total } & \multicolumn{3}{|c|}{ Rural } & \multicolumn{3}{|c|}{ Urban } \\
\hline percent of total population & Total & Male & Female & Total & Male & Female & Total & Male & Female \\
\hline Total Disability & 2.21 & 2.40 & 2.01 & 2.24 & 2.43 & 2.03 & 2.17 & 2.34 & 1.98 \\
\hline Seeing & 18.77 & 17.61 & 20.25 & 18.80 & 17.50 & 20.45 & 18.71 & 17.86 & 19.78 \\
\hline Hearing & 18.92 & 17.87 & 20.25 & 18.21 & 17.14 & 19.56 & 20.53 & 19.53 & 21.80 \\
\hline Speech & 7.45 & 7.49 & 7.40 & 7.00 & 7.06 & 6.92 & 8.49 & 8.48 & 8.52 \\
\hline Movement & 20.28 & 22.49 & 17.47 & 21.66 & 24.05 & 18.63 & 17.13 & 18.94 & 14.83 \\
\hline Mental Retardation & 5.62 & 5.81 & 5.37 & 5.50 & 5.68 & 5.28 & 5.87 & 6.10 & 5.58 \\
\hline Mental IIIness & 2.70 & 2.77 & 2.60 & 2.66 & 2.72 & 2.58 & 2.78 & 2.89 & 2.63 \\
\hline Any Other & 18.38 & 18.20 & 128.60 & 17.67 & 17.56 & 17.81 & 19.98 & 19.66 & 20.39 \\
\hline Multiple & 7.89 & 7.76 & 8.07 & 8.50 & 8.29 & 8.77 & 6.51 & 6.54 & 6.46 \\
\hline
\end{tabular}

Source: Census of India 2011

Table 02: Number of Disabled Children Identified with Special ref. to J\&K

\begin{tabular}{|c|c|c|c|c|c|c|c|c|c|c|c|c|c|c|}
\hline \multirow[t]{3}{*}{ \# } & \multirow[t]{3}{*}{ Districts } & \multirow{3}{*}{$\begin{array}{l}\text { Mentally } \\
\text { Retarded } \\
\text { Boys }\end{array}$} & \multirow{2}{*}{\multicolumn{2}{|c|}{$\begin{array}{l}\text { Visually } \\
\text { Impaired }\end{array}$}} & \multirow{2}{*}{\multicolumn{2}{|c|}{$\begin{array}{l}\text { Hearing } \\
\text { Impaired }\end{array}$}} & \multirow{2}{*}{\multicolumn{2}{|c|}{ Ortho }} & \multirow{2}{*}{\multicolumn{2}{|c|}{$\begin{array}{c}\text { Multiple } \\
\text { Disability }\end{array}$}} & \multirow{2}{*}{\multicolumn{4}{|c|}{ All Disabled Children }} \\
\hline & & & & & & & & & & & & & & \\
\hline & & & Girls & Boys & Girls & Boys & Girls & Boys & Girls & Boys & Girls & Boys & Girls & Total \\
\hline 1 & Kupwara & 314 & 221 & 607 & 419 & 396 & 329 & 662 & 492 & 285 & 252 & 2264 & 1714 & 3978 \\
\hline 2 & Baramulla & 866 & 721 & 883 & 606 & 799 & 562 & 1425 & 1006 & 0 & 0 & 3973 & 2895 & 6868 \\
\hline 3 & Leh & 31 & 103 & 143 & 128 & 122 & 100 & 270 & 225 & 0 & 0 & 647 & 554 & 1201 \\
\hline 4 & Budgam & 174 & 137 & 132 & 102 & 169 & 141 & 473 & 363 & 70 & 55 & 1018 & 796 & 1814 \\
\hline 5 & Anantnag & 722 & 226 & 544 & 351 & 395 & 314 & 689 & 505 & 518 & 392 & 2580 & 1788 & 4368 \\
\hline 6 & Pulwama & 437 & 546 & 667 & 475 & 412 & 307 & 1052 & 783 & 829 & 751 & 3683 & 2862 & 6545 \\
\hline 7 & Srinagar & 118 & 30 & 12 & 17 & 30 & 25 & 30 & 21 & 22 & 33 & 123 & 126 & 249 \\
\hline 8 & Kargil & 44 & 31 & 85 & 77 & 108 & 63 & 104 & 78 & 187 & 233 & 528 & 482 & 1010 \\
\hline 9 & Udampur & 296 & 162 & 473 & 282 & 327 & 237 & 779 & 434 & 414 & 242 & 2255 & 1357 & 3612 \\
\hline 10 & Doda & 266 & 222 & 294 & 165 & 230 & 169 & 270 & 217 & 479 & 265 & 1568 & 1038 & 2606 \\
\hline 11 & Poonch & 42 & 18 & 102 & 50 & 72 & 55 & 28 & 19 & 216 & 94 & 460 & 237 & 697 \\
\hline 12 & Rajouri & 126 & 87 & 186 & 145 & 141 & 126 & 307 & 227 & 111 & 82 & 871 & 667 & 1538 \\
\hline 13 & Jammu & 205 & 150 & 202 & 134 & 94 & 90 & 48 & 43 & 250 & 178 & 799 & 595 & 1394 \\
\hline 14 & Kathua & 65 & 50 & 87 & 55 & 50 & 40 & 128 & 71 & 160 & 128 & 490 & 344 & 834 \\
\hline & Jammu and Kashmir & 3706 & 2704 & 4417 & 3078 & 3345 & 2559 & 6265 & 4484 & 3541 & 2706 & 21259 & 15455 & 36714 \\
\hline
\end{tabular}


Earlier examination has would in general inspect the adapting of useless families, while families adapting effectively to emergencies were not adequately researched. As of late there has been a progressive change in the expert view of groups of formatively debilitated individuals. The solid idea of families adapting to bringing up a formatively incapacitated kid as unavoidably situated in a circumstance of emergency, stress and pathology has advanced towards multi-dimensional acknowledgment of many changed habits of adapting. This idea recognizes the need to explore and comprehend the reasons for such fluctuated adapting designs. Where once the emphasis was distinctly on the impaired youngsters, the most recent twenty years have seen an expanded interest in the whole family. In the United States this change is additionally communicated by enactment recognizing the part of families as the main lead for the turn of events and administration of impaired youngsters.

Furthermore, longitudinal exploration following parental responses from the second a crippled kid is conceived and analysing their adapting in different marks of time all through life is obviously missing. It is as of now acknowledged that adapting designs change over the diverse life phases of the formatively debilitated and their families. Assessment of upsetting circumstances at different life stages found that formatively debilitated youths structure the most troublesome time of pressure. Guardians' maturing and their drawn out non-standardizing parental job prompts the improvement of new issues requiring consideration. Logical discoveries here are not viable. A few specialists demonstrate decreasing help and expanding pressure, while different investigations show a chance for mental development and testing adapting measures. The inconsistency underscores the significance of following these families for the duration of their life expectancy and distinguishing defining moments requiring mediation. We can't deny the reality, that there is no tried method to assist guardians with dodging the stun and agony that go with openness of their youngster's impairment, yet the worry guardians need to face such difficulties with part of certainty and self-discipline without hearting the personality of the debilitated kid. Similarly encouraging group of people whether formal or casual has an extremely huge part in adapting such issues.

\section{Ways of Parenting a Child with disability}

As all we realize that "arriving at a position of expectation idealism requires some investment". It is a slow cycle that happens when we start to comprehend the inability and the worry youngster. We ought to comprehend that God has given us the endowment of a kid and nurturing is a stunning excursion. Zero in on being the best parent you can be. Love your kid. Your kid with incapacity is as yet unchanged great and remarkable blessing from God. Figure out how to value the things that fulfil your youngster. Search for your Child's qualities and develop them. Decide life time objectives for your youngster with a handicap. Set aside a few minutes for the entire family to partake in being together. Encompass yourself with individuals who get you and your youngster. Instruct your kid with respect to his instructive rights, protection, plans and other government plans in regards to their incapacity issues. Additionally, there are some presumed NGO too who give, directing and backing to such children. Take advices from specialists, clinicians, sociologists every now and then in regards to available resources of appropriate socialization of such kids.

Incapacity has been disregarded from the days of yore. Prior it involved isolation yet now it is accounted for wildly. In this paper the creators have attempted to show the thickness and greatness of the inability in factual structure. The statistical some portions of our examination have covers every one of the significant sorts of incapacities including number of males, female alongside the provincial and metropolitan differentiation of India. In the condition of specialty of this section, one of the parts manage the model of incapacity. It very well may 
be contended that none of the models can clarify incapacity in a comprehensive manner. Social model neglects to recognize biophysical causation and minority and hole model have various lines of translation. Hole model is by all accounts an idealistic kind when it accepts the contrast among capacity and assumption and clinical model can't be found a way into a logical model. So, one ought to be mindful so as to utilize the model as an edge of understanding. It is on the grounds that model identified with incapacity is just an optics having diverse interpretative purposes and application subsequently, handicap as a subject and an item is a sort of epistemological articles. The epistemological situation of the term incapacity is ought to be rethought. It is on the grounds that at the hour of dissecting the situation of incapacity from miniature and large-scale level, there is need to re-conceptualize handicap regarding wiped out Kumar et al. Diary of Disability Studies J. Handicap Stud., 2015 ought to be viewed as average folks. In India, the issue of inability has been overlooked from the days of yore. Prior it involved isolation yet now it is accounted for wildly. In this paper the creators have attempted to show the thickness and greatness of the incapacity in measurable structure. The statistical a piece of our investigation have covers every one of the significant kinds of inabilities including number of males, female alongside the rustic and metropolitan differentiation of India. In the condition of craft of this section, one of the parts manage the model of incapacity. It tends to be contended that none of the models can clarify handicap in a comprehensive manner. Social model neglects to recognize biophysical causation and minority and hole model have various lines of translation. Hole model is by all accounts an idealistic kind when it accepts the contrast among capacity and assumption and clinical model can't be found a way into an illustrative model. So, one ought to be mindful so as to utilize the model as a casing of translation. It is on the grounds that model identified with inability is just an optics having distinctive interpretative purposes and application thus, incapacity as a subject and an article is a sort of epistemological items. The epistemological situation of the term handicap is ought to be rethought. It is on the grounds that at the hour of dissecting the situation of inability from miniature and full-scale level, there is need to re-conceptualize incapacity concerning debilitated [7].

\section{Conclusion}

To finish up let we all approach with a positive outlook and deal with the debilitated ones like typical individuals. Allow us to emerge from customary social framework and think with a positive system to determine the issues and difficulties looked by our incapacitated populace and the worry families. We all need to function as friendly activists/social laborers and attempt our level best to share our hands in settling the issues and issues of regular masses, and the crippled populace.

\section{References}

1. J. Grue. Disability and discourse analysis. Ashgate Publishing, Ltd, 2015. World Health Organisation. Disabilities. Retrieved from

2. United Nations. Convention on the rights of persons with disabilities. Retrieved from disabilities/documents/convention/convoptprot

3. M. A. McColl, J. E. Bickenbach. Introduction to disability (Eds.). Bailliere Tindall, 1998.

4. R. Imrie. Rethinking the relationships between disability, rehabilitation, and society. Disable Rehabil. 1997,19(7), 263-271.

5. S. Barik. Disabled in India. ND: Adhyana Publishers \& Distributors, 2009.

6. Ministry of Social Justice and Empowerment. Government of India. Retrieved from

7. Government of India. Census of India, 2001. Retrieved from

8. National Sample Survey Organisation. Disabled persons in India, NSS 58th round (July- December 2002). National Sample Survey Organisation. 2003.

9. S. L. Gabel, S. Danforth. (Eds.). Disability and the politics of education: An international reader. Peter Lang, 2008.

10. D. Marks. Disability: Controversial debates and psychosocial perspectives. Psychology Press, 2014. 